\title{
NEURO-OPHTHALMIC FINDINGS IN BOTULISM TYPE B
}

\author{
P. R. SIMCOCK, S. KELLEHER and J. A. DUNNE \\ Blackpool
}

\begin{abstract}
SUMMARY
In June 1989, the largest recorded outbreak of foodborne botulism occurred in the United Kingdom. Twentyseven patients were affected during the outbreak with type $B$ botulism. A case note review of 14 patients admitted with this condition was performed and the neuroophthalmic findings are presented. Patients with severe disease presented with a combination of ocular and bulbar symptoms; in mild cases dysphagia was noted first and visual disturbance followed within 24 hours. Clustering of cases and bilaterality of cranial nerve signs aided in the diagnosis. Accommodative paresis and sixth cranial nerve palsy were frequent early signs. When there was respiratory paralysis and ventilatory failure, it occurred within 12 hours of the onset of a third cranial nerve palsy.
\end{abstract}

The organism responsible for botulism was discovered by Professor Emile van Ermengem in 1896 after investigating an illness in a group of musicians who had eaten raw salted ham after playing at a wake. Three of the musicians died. The organism, Clostridium botulinum, is an anaerobic, spore-forming, Gram-positive bacillus with a worldwide distribution. Food-borne botulism is rare in the United Kingdom. It is a potentially lethal condition that may present initially to an ophthalmologist due to visual impairment. The organism produces a polypeptide toxin with a molecular weight of 15000 daltons. It is one of the most potent toxins known to man. Three serologically distinct toxins (A, B and $\mathrm{E})$ are found in human botulism. The toxin acts on neuromuscular junctions and cholinergic sites within the autonomic nervous system (all ganglionic synapses, and post-ganglionic parasympathetic synapses) by binding irreversibly to receptors on the pre-synaptic membrane. This is followed by endocytosis, and through a process of enzymatic coupling the toxin prevents the normal calcium-associated quantal release of acetylcholine from the pre-synaptic nerve terminal.' Recovery can occur only by the formation of new axon terminals, with the regenerating axon forming contacts at the original synaptic sites. ${ }^{2}$

From: Victoria Hospital, Blackpool, UK

Correspondence to: Peter R. Simcock, FRCOphth, MRCP, Charing Cross Hospital, Fulham Palace Road, London W6 8RF, UK.
Patients present clinically within $12-36$ hours of ingestion of contaminated food. They may state that the food had an abnormal taste. One third of those affected may develop transient nausea and vomiting, abdominal pain and diarrhoea or constipation. There then develop oculobulbar signs followed by a descending paralysis. Clinical features include blurring of vision, dilated pupils, ptosis, external ophthalmoplegia, dysphagia and dysarthria. These features are often bilateral and may progress to weakness affecting the upper then the lower limbs, and in some cases respiratory muscle weakness requiring assisted ventilation. Important negative findings are a lack of fever, no sensory symptoms and no change in mental state. The differential diagnosis includes Guillain-Barré syndrome (however in this condition the paralysis is ascending), Miller-Fisher syndrome, myasthenia gravis, diphtheria, and brain stem stroke.

In June 1989, the largest recorded outbreak of foodborne botulism in the United Kingdom occurred in the North-West of England and North Wales. The neuroophthalmic features of this outbreak are now presented.

\section{PATIENTS AND METHODS}

A total of 27 patients ( 10 male, 17 female; age range 14 months to 74 years) were affected during the outbreak. The case notes of 11 patients admitted with botulism to the Victoria Hospital, Blackpool, and 3 patients admitted elsewhere were reviewed. All patients initially presented to the acute medical services. Clinical information was therefore obtained from the findings of the admitting physicians in all 14 patients. Eleven of the patients were subsequently reviewed by a consultant ophthalmologist with a formal orthoptic assessment.

\section{RESULTS}

Of the 27 patients affected, 25 had eaten one brand of hazelnut yoghurt before the onset of symptoms. Critchley et al. ${ }^{3}$ reviewed the main symptoms of all the patients in the outbreak and noted that $21(77.7 \%)$ complained of blurring of vision, 15 (55.5\%) complained of drooping lids and 8 (29.6\%) complained of double vision. The duration between consumption and onset of symptoms was 2 
Table I. Neuro-ophthalmic findings in 14 patients with type B botulism

\begin{tabular}{lcc}
\hline Clinical findings & $\begin{array}{c}\text { No. of } \\
\text { patients }\end{array}$ & \% bilateral \\
\hline Third cranial nerve palsy & & \\
Accommodative paresis & 13 & 100 \\
Ptosis & 12 & 92 \\
Ophthalmoparesis & 8 & 75 \\
Dilated pupils & 2 & 100 \\
Sixth cranial nerve palsy & 11 & 64 \\
Seventh cranial nerve palsy & 8 & 75 \\
Nystagmoid eye movements on lateroversions & 3 & 100 \\
Conjunctival injection & 4 & 75 \\
Epiphora & 4 & 100 \\
\hline
\end{tabular}

hours to 5 days (mean 1 day). In severe cases ocular and bulbar signs were present simultaneously; in milder cases, difficulty in swallowing was noted first and visual disturbance followed within 24 hours. Those patients admitted within 48 hours of the initial symptoms had both ocular and bulbar signs. Disease progression with spread of neurological deficit followed rapidly over the successive 3 days. Twelve patients were admitted to the Intensive Therapy Unit, 8 required artificial ventilation, and one 74-yearold woman died from aspiration pneumonia.

The neuro-ophthalmic finding of the 14 patients with case note review are summarised in Table I. Seven patients with ophthalmoparesis secondary to third cranial nerve palsy had restriction of elevation of the eye, and 1 patient had restriction of both adduction and elevation. No patient was documented as having a fourth cranial nerve palsy. Eleven patients had restriction of eye abduction. A full recovery of cranial nerve signs was noted in all the survivors in the case note review, with the exception of 1 patient who had a previously diagnosed $\mathrm{V}$ pattern esotropia. The speed of recovery of the ocular signs was related to the severity of the disease. Those patients requiring assisted ventilation had the most prolonged recovery, with a mean inpatient stay of 38 days compared with 14 days in patients not requiring ventilation.

\section{DISCUSSION}

The early ophthalmic signs of botulism included accommodative paresis and sixth cranial nerve palsy. The severity of the ophthalmoparesis was a good indicator of the overall severity and progression of the disease. When there was ventilatory failure, it occurred within 12 hours of the onset of a third cranial nerve palsy. Terranova et al. ${ }^{4}$ noted that sixth cranial nerve palsy may be the initial neurological manifestation of type B botulism. He also noted that 8 of $11(73 \%)$ patients with evidence of a third cranial nerve palsy eventually developed respiratory insufficiency.

Double vision was noted to be a symptom in only 8 (29.6\%) of the patients in the outbreak; however, 11 of the 14 patients in the case note review had evidence of sixth cranial nerve palsy. It is probable that associated lid ptosis reduced the frequency of this complaint in these patients.

Accommodative paresis was seen in 13 of the 14 (93\%) case notes reviewed and symptoms of blurring of vision were noted in $21(77.7 \%)$ of the patients in the outbreak. A more benign form of type B botulism has been reported where the major symptom was blurring of vision, together with a dry mouth and dry eye and no progression to a descending paralysis. ${ }^{5-7}$

Three patients had nystagmoid eye movement on lateral gaze. Hedges et al. ${ }^{8}$ examined 2 patients with botulism who had rapid quivering eye motions during attempts to re-fixate laterally placed objects. Oculographic studies showed multiple hypometric saccades and Hedges et al. postulated that the toxin limits the duration of saccadic burst innervation to the extraocular muscles.

In this outbreak there was a wide dispersion of cases geographically which initially added to the difficulty in diagnosis. There were four family groups with the disease (together with one cat who remained well after eating the remains of a yoghurt carton!) Clustering of cases, together with rapid onset of symptoms and symmetry of physical findings, all suggest the clinical diagnosis. Eighty-seven per cent of neuro-ophthalmic signs in the case notes reviewed were bilateral.

Public Health Laboratory investigations showed that the processing of the hazelnut conserve for the yoghurt was inadequate to destroy the Clostridium botulinum spores. Type B toxin was identified (by the mouse bioassay test) from the stool of 1 patient, 1 tin of hazelnut puree, and 2 cartons of hazelnut yoghurt from the patient's home. ${ }^{9}$ All serological tests for botulism in affected patients were negative.

Some unusual features of the outbreak were noted, including sore throats in 7 patients, watering eyes in 4 , and fever in 8. Electrodiagnostic tests were also unusual in that they showed evidence of segmental demyelination as seen in post-infectious neuropathy. Classical electrodiagnostic findings in this condition show normal motor and sensory conduction velocities, with reduced amplitude of the evoked compound muscle action potential in affected muscles, with increment in the muscle action potential with rapid repetitive nerve stimulation $(50 \mathrm{~Hz})$ or after exercise (as also seen in other pre-synaptic disorders such as Eaton-Lambert syndrome). ${ }^{10,11}$

Medical treatment of botulism is essentially supportive. Antitoxin has been shown only to shorten the duration of illness in type E botulism, but it should still be given to patients with botulism as soon as the diagnosis is suspected as it can only act before the toxin is irreversibly bound to its receptor on the pre-synaptic membrane. ${ }^{12.13}$ Adverse reaction to the antitoxin may be seen in up to $20 \%$ of patients. Guanidine is a compound that enhances release of acetylcholine from the pre-synaptic nerve terminal. It has been used in botulism but has only a slight effect on limb and ocular muscles and no effect on respiratory muscle. $^{14}$

Patients presenting with oculobulbar symptoms may undergo a tensilon test to exclude myasthenia gravis, but false positives may occur in mild forms of botulism. . $^{3.14-16}$

Clinical improvement occurs over weeks to months. In the United States the mortality from this condition is 
$7.5 \% .^{17}$ In less well developed countries the mortality is higher. ${ }^{18}$ The combination of poor oropharyngeal function, respiratory muscle paralysis and a paralytic ileus results in a high risk of aspiration pneumonia, with subsequent respiratory failure and septicaemia. Patients with suspected botulism should have regular monitoring of respiratory function, but care should be taken with conventional respiratory monitoring in the presence of orofacial weakness. ${ }^{19}$

There are some clinical differences between the three neurotoxins producing botulism. Type E botulism is usually associated with eating seafood, and pupillary abnormalities and ptosis may be seen as early signs. ${ }^{20-2.3}$ Preceding gastrointestinal symptoms are more prevalent in type $\mathrm{E}$ and type $\mathrm{B}$ botulism. ${ }^{24}$ Type $\mathrm{A}$ botulism is the most severe form of the disease and carries the highest need for ventilatory support and also has the highest mortality. ${ }^{16,25-28}$

The most important aspect of management of an outbreak of food-borne botulism, however, is the early recognition of the condition, and an appropriate public health investigation to determine the source of the outbreak and prevent further spread of the disease.

Key words: Botulism, Ophthalmoplegia, Pupils, Vision disorders.

\section{REFERENCES}

1. Mallart A, Molgo J, Angaut-Petit D, Thesleff S. Is the internal calcium regulation altered in type $A$ botulinum toxinpoisoned motor endings? Brain Res 1989:479:167-71.

2. Tsukihoto M, Kinoshita I, Mori M, et al. Ultrastructural study of the motor end-plate in botulism and Lambert-Eaton myasthenia syndrome. J Neurol Sci 1987;81:197-213.

3. Critchley EM, Hayes PJ, Isaacs PE. Outbreak of botulism in north west England and Wales, June 1989. Lancet 1989;2:849-53.

4. Terranova W, Palumbo JN, Breman JG. Ocular findings in botulism type B. JAMA 1979;241:475-7.

5. Konig H, Gassman HB, Jenzer G. Ocular involvement in benign botulism B. Am J Ophthalmol 1975;80:430-2.

6. Jedelhauser PH. Botulismus-Verlaufsbeobachtungen mit Schwerpunkt auf der ophthalmologischen Symptomatik. Klin Monatsbl Augenheilkd 1985;186:18-24.

7. Schubart P, Kasperski S, Schroder P. Augenbeteiligung bei Botulismus. Klin Monatsbl Augenheilkd 1985;187:142-3.

8. Hedges TR, Jones A, Stark L, Hoyt WF. Botulin ophthalmoplegia: clinical and oculographic observations. Arch Ophthalmol 1983;101:211-3.

9. O’Mahony M, Mitchell E, Gilbert RJ, Hutchinson DN, Begg NT, Rodhouse JC, Morris JE. An outbreak of food-borne botulism associated with contaminated hazelnut yoghurt. Epidemiol Infect 1990;104:389-95.
10. Gutmann L, Bodensteiner J, Gutierrez A. Electrodiagnosis of botulism. J Pediatr 1992;121:835.

11. Ehrenreich H, Garner CG, Witt TN. Complete bilateral internal ophthalmoplegia as sole clinical sign of botulism: confirmation of diagnosis by single fibre electromyography. J Neurol 1989;236:243-5.

12. Merson MH, Hughes JM, Dowell VR, et al. Current trends in botulism in the United States. JAMA 1979;229:1305-8.

13. Tacket CO, Shandera WY, Mann JM, Hargrett NT, Blake PA. Equine antitoxin use and other factors that predict outcome in type A food-borne botulism. Am J Med 1984;76:794-8.

14. Cherington M. Botulism: ten-year experience. Arch Neurol 1974:30:432-7.

15. Ryan DW, Cherington M. Human type A botulism. JAMA 1971;216:513-4.

16. St Louis ME, Peck SHS, Bowering D, Morgan GB, Blatherwick J, Banerjee S, et al. Botulism from chopped garlic: delayed recognition of a major outbreak. Ann Intern Med 1988; 108:363-8.

17. MacDonald KL, Cohen ML, Blake PA. The changing epidemiology of adult botulism in the United States. Am J Epidemiol 1986;124:794-9.

18. Weber JT, Hibbs RG Jr, Darwish A, et al. A massive outbreak of type E botulism associated with traditional salted fish in Cairo. J Infect Dis 1993;167:451 -4.

19. Critchley EMR, Mitchell JD. Human botulism. Br J Hosp Med 1990;43:290-2.

20. Wainwright RB, Heyward WL, Middaugh JP, Hatheway CL, Harpster AP, Bender TR. Food-borne botulism in Alaska, 1947-1985: epidemiology and clinical findings. J Infect Dis 1988;157:1158-62.

21. Koenig MG, Spickard A, Cardella MA, et al. Clinical and laboratory observations on type E botulism in man. Medicine 1964:43:517-45.

22. Whittaker RL, Gilbertson RB, Garrett AS. Botulism type E: report of eight simultaneous cases. Ann Intern Med 1964;61:448-54.

23. Ball AP, Hopkinson RB, Farrell ID, et al. Human botulism caused by Clostridium botulinum type E: the Birmingham outbreak. Q J Med 1979;48:473-91.

24. Donadio JA, Gangarosa EJ, Faich GA. Diagnosis and treatment of botulism. J Infect Dis 1971:124:108-12.

25. Shin Y, Chao SY. Botulism in China. Rev Infect Dis 1986:8:984-90.

26. Hauschild AHW. Clostridium botulinum. In: Doyle MP, editor. Food-borne bacterial pathogens. New York: Marcel Dekker, 1989: 111-89.

27. Hughes JM, Blumenthal JR, Merson MH, et al. Clinical features of types A and B food-borne botulism. Ann Intern Med 1981;95:442-5.

28. Woodruff BA, Griffin PM, McCroskey LM, et al. Clinical and laboratory comparison of botulism from toxin types A, B and E in the United States, 1975-1988. J Infect Dis 1992; 166:1281-6. 